\title{
Case report of the fourth laparoscopic liver resection and review of repeat laparoscopic resection for recurrent hepatocellular carcinoma in cirrhotic liver
}

\author{
Zenichi Morise $^{1}$, Masashi Isetani ${ }^{2}$, Norihiko Kawabe ${ }^{2}$, Hirokazu Tomishige ${ }^{2}$, Hidetoshi Nagata ${ }^{2}$, Satoshi Arakawa $^{2}$, \\ Masahiro Ikeda², Kenshiro Kamio²
}

${ }^{1}$ Department of Surgery, Fujita Health University School of Medicine, Toyoake, Aichi 470-1192, Japan.

${ }^{2}$ Department of Surgery, Fujita Health University Banbuntane Houtokukai Hospital, Nagoya, Aichi 454-8509, Japan.

Correspondence to: Prof. Zenichi Morise, Department of Surgery, Fujita Health University School of Medicine, 1-98 Dengakugakubo Kutsukakecho, Toyoake, Aichi 470-1192, Japan. E-mail: zmorise@fujita-hu.ac.jp

How to cite this article: Morise Z, Isetani M, Kawabe N, Tomishige H, Nagata H, Arakawa S, Ikeda M, Kamio K. Case report of the fourth laparoscopic liver resection and review of repeat laparoscopic resection for recurrent hepatocellular carcinoma in cirrhotic liver. Hepatoma Res 2016;2:253-8.

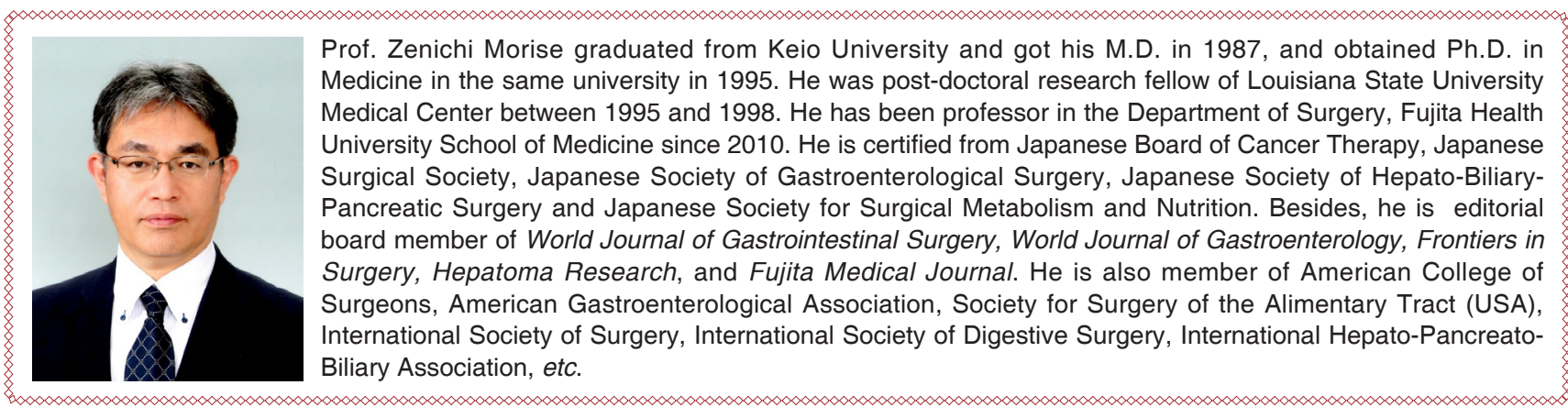

Article history:

Received: 06-04-2016

Accepted: 15-07-2016

Published: 19-09-2016

Key words:

Laparoscopic liver resection,

repeat liver resection,

hepatocellular carcinoma,

liver cirrhosis,

anatomical liver resection,

subsegmentectomy

\begin{abstract}
A 73-year-old woman with liver cirrhosis caused by hepatitis $\mathrm{C}$ virus (HCV) underwent treatment of three hepatocellular carcinomas (HCCs) in liver segment 4, following three previous laparoscopic liver resections (LLRs) over 73 months. Contrast-enhanced computed tomography showed three $0.5-1.2 \mathrm{~cm}$ HCCs deep within the portal territories of subsegments $4 \mathrm{a}$ and $4 \mathrm{~b}$. The patient underwent laparoscopic resection of $4 \mathrm{a}$ and $4 \mathrm{~b}$, with the preservation of the portal branch to $4 \mathrm{c}$, after minimal adhesiolysis around segment 4 . The operation lasted $284 \mathrm{~min}$, there was $50 \mathrm{~mL}$ of intra-operative bleeding and her recovery was uneventful. She was well, had experienced no recurrence and was HCV-negative, after taking oral antiHCV therapy, 21 months later. LLR is associated with fewer adhesions after surgery and requires less adhesiolysis, because the laparoscope and forceps can be used in the small spaces between adhesions. The present patient underwent four LLRs over 6 years without severe deterioration of liver functional reserve. LLR is a useful localized therapy, which can be performed repeatedly and may prolong the survival of patients with multicentric metachronous HCCs.
\end{abstract}




\section{INTRODUCTION}

Since the first successful report of laparoscopic liver wedge resection in 1991, ${ }^{[1]}$ laparoscopic liver resection (LLR) has been thought to be a "less invasive" procedure than open liver resection. Use of this technique is especially beneficial for patients with concurrent hepatocellular carcinoma (HCC) and chronic liver disease (CLD) ${ }^{[2-4]}$ However, accumulated experience of this technique and technological developments have facilitated the expansion of the indications for LLR. ${ }^{[5-7]}$ It is becoming clear that the magnified caudal view offered by laparoscopy allows improved visualization, especially for the hilar and dorsal area of the liver, and is thus beneficial for the dissection of hilar Glissonian pedicles and the inferior vena cava (IVC)..$^{[7-9]}$ LLRs of major hepatectomy and, even, with combined resection of major hepatic veins are now increasingly reported, ${ }^{[10-12]}$ despite the latter previously being a contraindication. Reports of repeated LLR procedures ${ }^{[13-16]}$ are also increasing. However, these reports have generally included both cases of HCC with CLD and of metastatic disease without background liver disease. ${ }^{[17-21]}$ The indication and efficacy of repeated LLR for HCC in a setting of CLD alone has yet to be fully determined. Here we present a case report of a fourth LLR for recurrent HCCs in cirrhotic liver and review the previously reported cases of repeat LLR for the treatment of $\mathrm{HCC} .{ }^{[22,23]}$

\section{CASE REPORT}

A 73-year-old woman with hepatitis C virus (HCV)related liver cirrhosis (LC) was admitted to our department for treatment of three lesions in liver segment 4 . These were revealed by contrast-enhanced computed tomography (CT) examination undertaken during the follow up to three LLRs that were performed 73, 45, 23 months previously [Figure 1]. The patient had no history of hepatic encephalopathy, ascites (except immediately postoperatively) and no specific treatment history except that of the liver disease.

The laboratory data showed decreased white blood cell and platelet counts $(1,800$ and $68,000 / \mu \mathrm{L}$, respectively) and plasma albumin $(3.5 \mathrm{~g} / \mathrm{dL})$ and mild elevations in plasma aspartate transaminase (AST, $76 \mathrm{IU} / \mathrm{L}$ ) and alanine transaminase (ALT, $71 \mathrm{IU} / \mathrm{L})$. The prothrombin time $(78 \%)$, plasma levels of total bilirubin $(0.6 \mathrm{mg} / \mathrm{dL})$ and prothrombin induced by vitamin $\mathrm{K}$ absence-II (PIVKAII, $9 \mathrm{mAU} / \mathrm{mL}$ ) were within their normal ranges, but alpha-fetoprotein (AFP) showed a mild elevation (to $67.5 \mathrm{ng} / \mathrm{mL}$ ). The 15-min value during the clearance rate of indocyanine green loading test (ICG-R15) was $24.1 \%$; this had not deteriorated over the 73 months since the first LLR [Table 1].

Table 1: Perioperative clinical variables associated with each LLR

\begin{tabular}{ccccc}
\hline & 1st & 2nd & 3rd & 4th \\
\hline ICG-R15 & 20.9 & 27.5 & 27.0 & 24.1 \\
Bleeding (mL) & 35 & 30 & NC & 50 \\
Operating time (min) & 288 & 168 & 216 & 274 \\
POHS (days) & 11 & 9 & 9 & 8 \\
\hline
\end{tabular}

LLR: laparoscopic liver resection; ICG-R15: 15 min value during the clearance rate of indocyanine green loading test; 1 st: ICG-R15 and perioperative course of first LLR; 2nd: ICG-R15 and perioperative course of second LLR; 3rd: ICG-R15 and perioperative course of third LLR; 4th: ICG-R15 and perioperative course of fourth LLR; NC: low, unquantifiable; POHS: postoperative hospital stay
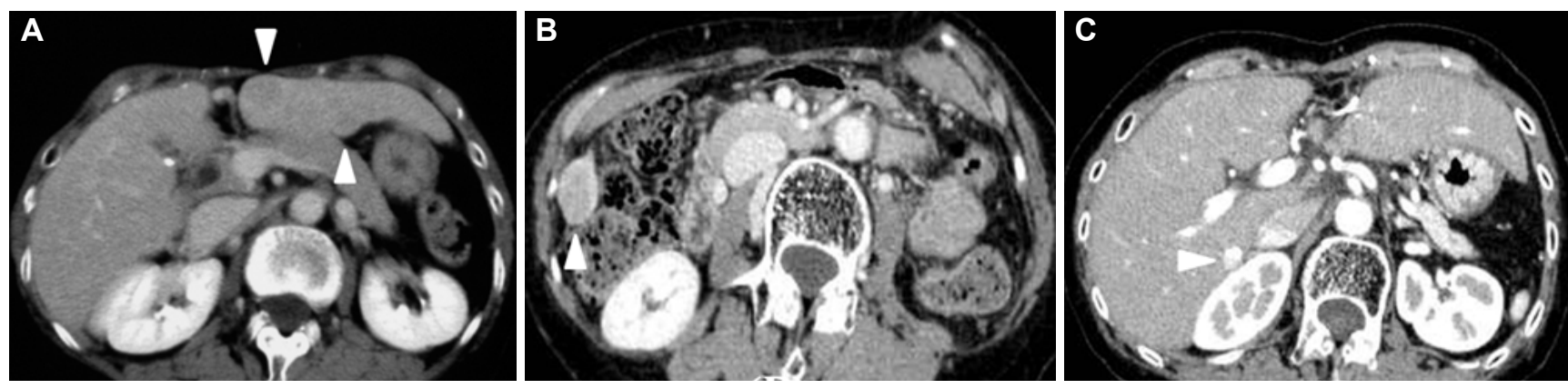

Figure 1: Contrast-enhanced computed tomography (CT) examination at the first (A), second $(B)$ and third $(C)$ laparoscopic liver resection. $(A)$ : The patient's first laparoscopic liver resection [LLR, extended segment 3 (S3) segmentectomy] was performed for two hepatocellular carcinomas (HCCs, $18 \mathrm{~mm}$ and $12 \mathrm{~mm}$ in size) in S3 and at the border of S2-3, 73 months before the fourth LLR. Contrast-enhanced CT examination (venous phase) shows two lesions (arrowheads).(B): The patient's second LLR (partial resection of S5-6) was performed for HCC (30 mm in size) on the edge of the border of S5-6, 45 months before the fourth LLR. Contrast-enhanced CT examination (portal phase) shows the lesion (arrowhead). (C): The patient's third LLR (partial resection of S7-1) was performed for a HCC $(8 \mathrm{~mm})$ next to the inferior vena cava, 23 months before the fourth LLR. Contrast-enhanced CT examination (portal phase) shows the lesion with lipiodol accumulation (arrowhead); this had been previously treated by trans-arterial chemo-embolization 

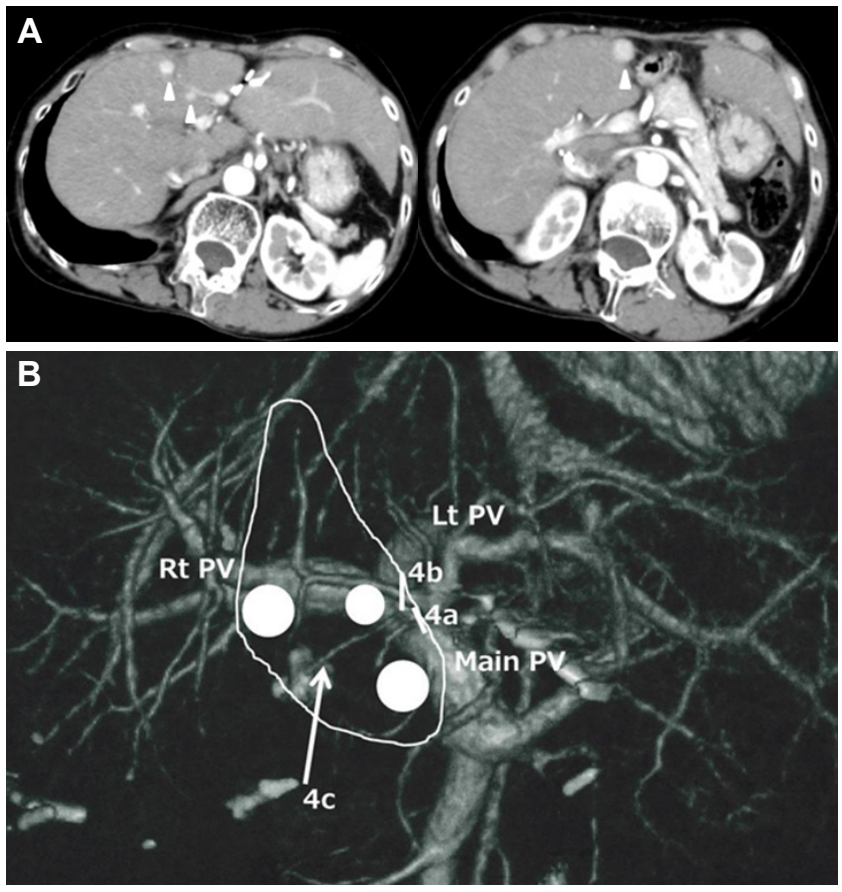

Figure 2: Contrast-enhanced computed tomography (CT) examination at the fourth laparoscopic liver resection $(A)$ and schema of the surgical resection plan (B). (A): A contrast-enhanced CT examination demonstrated three (12, 7 and $5 \mathrm{~mm}$ ) lesions (arrowheads) in the deep area of liver segment 4 , inside the portal territories of subsegments $4 a$ and 4b. (B): A laparoscopic anatomical liver resection of subsegments $4 \mathrm{a}$ and $4 \mathrm{~b}$ was planned for the removal of possible disseminated tumor cells in the portal territories and the preservation of maximum liver volume. Glissonian branches to subsegments $4 \mathrm{a}$ and $4 \mathrm{~b}$ were divided at their roots (bars), while $4 \mathrm{c}$ was preserved on the bottom of the resection plane (arrow). White circles indicate tumors

CT demonstrated three $0.5-1.2-\mathrm{cm}$-sized low-density lesions in the deeper region of liver segment 4 , within the portal territories of subsegments $4 \mathrm{a}$ and $4 \mathrm{~b}$. The lesions were enhanced with contrast during the arterial phase and washout of the enhancement was observed in the portal-venous phase [Figure 2]. Laparoscopic anatomical resection of subsegments $4 \mathrm{a}$ and $4 \mathrm{~b}$ were planned, with the preservation of the portal branch to $4 \mathrm{c}$ on the bottom of the resection plane. This procedure would ensure a surgical margin appropriate to the diagnosis of multiple HCCs in cirrhotic liver, given the possibility for the removal of tumor cell dissemination in the portal territory, but also preserve the maximum possible liver volume [Figure 2].

During the surgery, the patient was placed in a supine position. The first trocar port was introduced by minilaparotomy on the umbilicus; $\mathrm{CO}_{2}$-pneumoperitonium (8$12 \mathrm{mmHg}$ ) was established through this port and it was also used for laparoscopy. Three other $12-\mathrm{mm}$ ports and one 8-mm port were placed in the left upper abdomen and used for introducing surgeons' forceps, electrical devices (SonoSurg ${ }^{\circledR}$, BiClamp ${ }^{\circledR}$ bipolar forceps and irrigation monopolar electrical cautery using soft-mode coagulation), clips and a Cavitron ultrasonic surgical
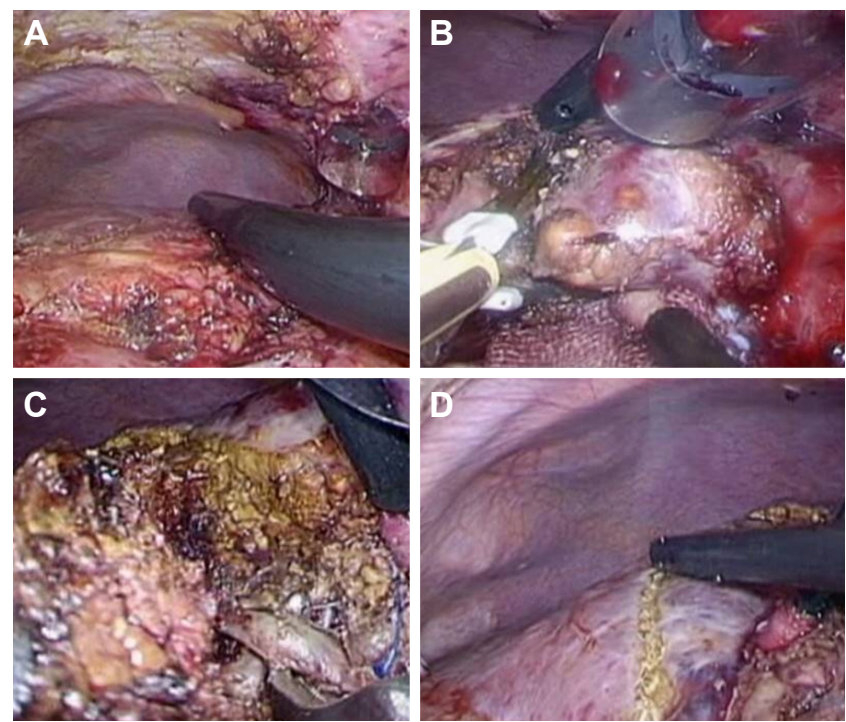

Figure 3: Intraoperative findings. (A): Before the liver transection, minimum adhesiolysis was performed around the area of segment 4 of the liver. Intraoperative ultrasonography was used to demonstrate the locations of the tumors and the line of the umbilical plate, which were marked. (B): The liver parenchymal transection was commenced along a line to the right side of the umbilical plate. (C): During transection along this line, the Glissonian branches to subsegment $4 \mathrm{a}$, and subsequently, $4 \mathrm{~b}$, were encircled and divided. (D): After dividing the branches to subsegments $4 \mathrm{a}$ and $4 \mathrm{~b}$, the area containing the hepatocellular carcinomas was clearly recognized as an ischemic area, prior to resection

aspirator. The Pringle maneuver was not applied to this patient. After minimum adhesiolysis around segment 4 , intraoperative ultrasonography was performed and the locations of the tumors and the line of the umbilical plate were marked [Figure 3A].

Transection of the liver parenchyma was commenced to the right of the line of the umbilical plate [Figure 3B]. During the transection, the Glissonian branches supplying subsegments $4 a$, and subsequently $4 b$, were encircled and divided [Figure $3 \mathrm{C}$ ]. After dividing the branches to $4 \mathrm{a}$ and $4 \mathrm{~b}$, the area containing the HCCs was clearly recognized as an ischemic area, in advance of resection [Figure 3D]. The ischemic area was resected laparoscopically, leaving the Glissonian branch to subsegment 4c exposed deep to the transection plane [Figure 4A]. The operation took $284 \mathrm{~min}$ and $50 \mathrm{~mL}$ of blood was lost intra-operatively.

Pathological examination of the three tumors identified them to be well-differentiated HCCs with fibrous capsules, but without vessel invasion, surrounded by grade F4 liver cirrhosis [Figure 4].

The patient recovered uneventfully and she was well, without recurrence, 21 months after surgery. Furthermore, she was then HCV-negative, having been taking a newly developed oral anti-HCV therapy (Daclatasvir/Asunaprevir). 

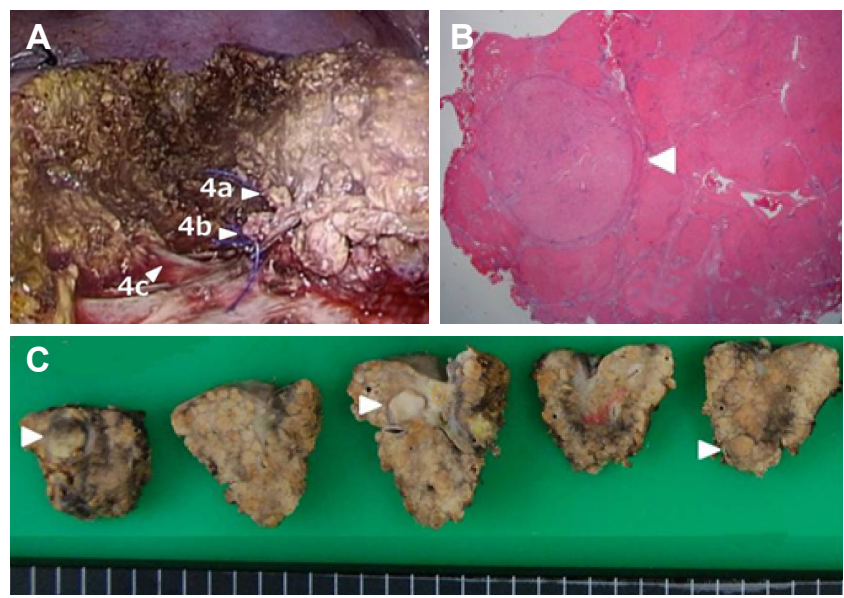

Figure 4: Intra-operative findings after resection (A), pathological findings (B), and examination of the resected specimen (C). (A): The area was resected laparoscopically, with the Glissonian branch of subsegment $4 \mathrm{c}$ being exposed on the bottom of the transection plane. The sites labelled $4 \mathrm{a}$ and $4 \mathrm{~b}$ indicate the stumps of the Glissonian pedicles of subsegments $4 a$ and $4 b$. The site labelled $4 c$ indicates the Glissonian branch supplying subsegment 4c, exposed on the bottom of the transection plane. (B): Pathologically, the three tumors were well-differentiated hepatocellular carcinomas with fibrous capsules but without vessel invasion, surrounded by stage F4 tissue (liver cirrhosis)

\section{DISCUSSION}

The development of post-operative adhesion is known to increase the surgical time in subsequent surgeries, as a result of the need for adhesiolysis, the risk of intraoperative complications ${ }^{[24]}$ and the possibility of conversion from laparoscopic procedure to laparotomy. ${ }^{[25]}$ Although a history of abdominal surgery had been considered a contraindication for laparoscopic surgery in the early days of the procedure, improvements in technique and instrumentation have more recently permitted many laparoscopic procedures to be safely applied to such patients. ${ }^{[24,26-29]}$ However, LLR remains a technically demanding procedure and the indications for and efficacy of repeat LLRs are still under discussion. Successful liver resection requires adequate adhesiolysis and mobilization of the involved liver area. Adhesions can be obstacles to the visualization and dissection of the hepatoduodenal ligament and hilar area, which are often crucial steps in LLR. Liver capsule bleeds easily during adhesiolysis and mobilization, creating a suboptimal surgical field, in addition to the increase in blood loss. ${ }^{[30]}$

The outcomes of repeated LLRs have been reported in several small case series. ${ }^{[13-16]}$ However, these studies often included both HCC/CLD and metastatic patients,,$^{[17-21]}$ while the clinical settings for repeated LLR are quite different in HCC/CLD and metastatic patients. Patients with metastasis sometimes undergo major liver resection involving the handling of Glissonian pedicles in soft, congested and/or fatty parenchyma. Conversely,
HCC/CLD patients often undergo minor resection of the hard, fibrotic liver, which has a poor functional reserve and is surrounded by blood or lymphatic collateral vessels, which should be preserved. The number of reported repeat LLR cases for HCC/LLR patients is very small, and these are summarized in Table 2.

There are three previous reports of repeat LLR focused for HCC/CLD patients. Belli et al., ${ }^{[13]} \mathrm{Hu}$ et al., ${ }^{[15]}$ and Kanazawa et al. ${ }^{[22]}$ reported 12, 6, and 20 cases, respectively. They all concluded that repeat LLR for recurrent HCC in cirrhotic patients is a safe and feasible procedure. Belli et al. ${ }^{[13]}$ reported that the surgical time for repeat LLR was shorter and the adhesiolysis was easier for patients previously treated using LLR compared to open LR (OLR), and also detailed the advantages of the minimally invasive approach for managing the chronic oncologic sequelae of cirrhosis. Kanazawa et al. ${ }^{[22]}$ compared repeat LLR to repeat OLR in $n=20$ groups of patients and concluded that postoperative morbidity and the duration of postoperative hospitalization have been decreased by the introduction of LLR for patients with recurrent $\mathrm{HCC}$.

We previously reported that LLR is useful for patients with severe liver dysfunction, as it minimizes disturbance of the collateral blood/lymphatic flow caused by laparotomy and liver mobilization, and the mesenchymal injury caused by compression of the liver. ${ }^{[31,32]}$ Thus, LLR limits the occurrence of complications, such as massive ascites, which can lead to postoperative liver failure. ${ }^{[3]}$ We also reported that the smaller working space required for LLR necessitated less adhesiolysis, with a direct approach to the region affected by the tumor being possible in repeat LLR. ${ }^{[20]}$ This also meant that patients undergoing repeat LLR had similar perioperative results to patients without a history of surgery, especially in the case of minor resections for HCC/CLD patients. The majority of the patients described in previous reports of repeat LLR for HCC/CLD underwent minor resection as a repeat LLR. Therefore the influences of alterations to hilar and intrahepatic anatomy from the first hepatectomy should have been relatively small. Since alterations in hilar and intrahepatic vascular supply would greatly impact on the second hepatectomy, further consideration of a role for major or anatomical repeat LLR is needed. However, results to date suggest that a clear advantage of LLR for minor repeat resections of impaired liver is that it only requires minimal adhesiolysis.

In the case reported here, the patient underwent four LLRs over six years without severe deterioration of liver functional reserve, represented by the 
Table 2: Summary of previous reports of repeat laparoscopic hepatectomy that included cases of hepatocellular carcinoma

\begin{tabular}{|c|c|c|c|c|c|c|c|c|c|c|c|}
\hline Authors & $n$ & Age (year) & Disease & $\begin{array}{c}\text { First Hx } \\
\text { (open:Iap) }\end{array}$ & Procedure & $\begin{array}{l}\text { Bleeding } \\
(\mathrm{mL})\end{array}$ & $\begin{array}{l}\text { Operating } \\
\text { time (min) }\end{array}$ & $\begin{array}{l}\text { Con. } \\
(n)\end{array}$ & $\begin{array}{l}\text { POHS } \\
\text { (days) }\end{array}$ & Morbidity & Mortality \\
\hline $\begin{array}{l}\text { Belli et al[.113]* } \\
(2009)\end{array}$ & 12 & $69(58-75)$ & $\mathrm{HCC}$ & $4: 8$ & $\begin{array}{c}\operatorname{LLS}(n=5), \\
\operatorname{Pt}(n=4), \\
\operatorname{Seg}(n=3)\end{array}$ & $\begin{array}{c}297 \pm 134 \\
272.2 \pm 120\end{array}$ & $\begin{array}{c}114.4 \pm 11.0 \\
63.9 \pm 13.3\end{array}$ & 1 & $\begin{array}{l}7.4 \pm 2.5 \\
6.2 \pm 3.0\end{array}$ & $26.6 \%$ & $0 \%$ \\
\hline $\begin{array}{l}\text { Hu et al. } .^{[17]} \\
(2011)\end{array}$ & 6 & $49(46-61)$ & $\mathrm{HCC}$ & $\begin{array}{c}3: 3 \\
\text { (Lap RFA, } \\
n=2 \text { ) }\end{array}$ & $\begin{array}{l}\operatorname{LLS}(n=2) \\
\operatorname{Pt}(n=4)\end{array}$ & $283.3 \pm 256.3$ & $140.8 \pm 35.7$ & 0 & $5.67 \pm 1.63$ & $16.7 \%$ & $0 \%$ \\
\hline $\begin{array}{l}\text { Shafaee et al. }{ }^{[16]} \\
(2011)\end{array}$ & 76 & $61(29-82)$ & $\begin{array}{c}\text { Met }(n=63) \text {, } \\
\text { HCC }(n=3) \text {, } \\
\text { others } \\
(n=10)\end{array}$ & $28: 44$ & $\begin{array}{c}\text { LLS }(n=4), \\
\text { Pt, seg } \\
(n=53), \\
\text { above-seg } \\
(n=19)\end{array}$ & $300(0-5000)$ & $180(80-570)$ & 8 & $6(2-42)$ & $26 \%$ & $0 \%$ \\
\hline $\begin{array}{l}\text { Ahn et al.[15] } \\
(2011)\end{array}$ & 4 & $57(54-60)$ & $\begin{array}{c}\operatorname{HCC}(n=3), \\
\operatorname{Met}(n=1)\end{array}$ & $0: 4$ & $\begin{array}{l}\operatorname{LLS}(n=1) \\
\operatorname{Pt}(n=3)\end{array}$ & $481.7 \pm 449.5$ & $312.3 \pm 158.4$ & 1 & $10.6 \pm 7.4$ & $23.4 \%$ & $0 \%$ \\
\hline $\begin{array}{l}\text { Tsuchiya et al. }{ }^{[19]} \\
(2012)\end{array}$ & 3 & $73(52-79)$ & $\mathrm{HCC}$ & $0: 3$ & & 281.3 (mean) & 264.6 (mean) & 0 & 8.6 (mean) & & $0 \%$ \\
\hline $\begin{array}{l}\text { Kanazawa et al.[20] } \\
\text { (2013) }\end{array}$ & 20 & 70 (46-83) & $\mathrm{HCC}$ & $15: 5$ & $\mathrm{Pt}$ & $78(1-1500)$ & $239(69-658)$ & $\begin{array}{c}2 \\
\text { (HALS) }\end{array}$ & $9(5-22)$ & $5 \%$ & $0 \%$ \\
\hline $\begin{array}{l}\text { Shelat et al. }{ }^{[23]} \\
\text { (2014) }\end{array}$ & 20 & $57.5(23-79)$ & $\begin{array}{l}\text { HCC }(n=2) \text {, } \\
\text { Met }(n=16) \\
\text { others }(n=2)\end{array}$ & $0: 20$ & $\begin{array}{c}\text { Minor }(n=14) \\
\text { Major }(n=6)\end{array}$ & $\begin{array}{c}400 \\
\text { (IQR 150- } \\
200)\end{array}$ & $\begin{array}{c}285 \\
\text { (IQR 195-360) }\end{array}$ & 3 & $4(1-57)$ & $10 \%$ & $0 \%$ \\
\hline $\begin{array}{l}\text { Isetani et al.[22] } \\
(2015)\end{array}$ & 12 & $70(57-81)$ & $\begin{array}{c}\text { HCC }(n=8) \text {, } \\
\text { Met }(n=2), \\
\text { others }(n=2)\end{array}$ & $8: 4$ & $\begin{array}{c}\text { Pt }(n=9) \\
\text { Subseg } \\
(n=3)\end{array}$ & $\begin{array}{c}50 \\
\text { (NC-840) }\end{array}$ & $301(104-570)$ & 0 & $12(9-30)$ & $0 \%$ & $0 \%$ \\
\hline
\end{tabular}

Data are expressed as median (range) or mean \pm standard deviation, unless stated otherwise. *In the paper by Belli et al., ${ }^{[13]}$ operating time, bleeding and POHS are described separately for patients whose previous hepatectomy was open (upper) or laparoscopic (lower). Con: conversion to laparotomy; HALS: hand-assisted laparoscopic surgery; HCC: hepatocellular carcinoma; IQR: interquartile range; LLS: left lateral sectorectomy; Met: metastasis; Minor: resection of 2 segments or less; Major: resection of more than 2 segments; NC: low, unquantifiable; POHS: postoperative hospital stay; Pt: partial resection; RFA: radiofrequency ablation; Seg: segmentectomy; Subseg: subsegmentectomy

ICG-R15, and became HCV-negative, after taking a newly developed oral anti-HCV therapy. The patient remained in compensated LC throughout the period in which the four LLRs were performed. As a result, and because of the shortage of cadaver donors in Japan, liver transplantation was not undertaken. During both the first and fourth LLRs, minor anatomical resections (extended segment 3 segmentectomy and $4 \mathrm{ab}$ subsegmentectomy, respectively) were undertaken to remove multiple tumors in the same portal territories, because the patient's liver functional reserve (estimated by ICGR15) was insufficient to support sectionectomy or more extended resection. Furthermore, ablation therapy was not performed for the protuberant tumors necessitating the first and second LLRs and for the tumor adjacent to the IVC at the time of third LLR, owing to the technical challenges associated. Transarterial chemo-embolization (TACE) was used prior to the third LLR, but the target tumor had regrown six months after TACE; therefore, LLR was selected for the follow-up treatment.

LLR is highly suitable for repeated laparoscopic partial or local anatomical LR for the treatment of multicentric metachronous HCCs within impaired liver and for surface HCC in severe LC. ${ }^{[31,32]}$ The deterioration of liver function should be minimized with the reduced adhesiolysis and dissection required during a laparoscopic approach. In addition, LLR better prepared patients both physically and psychologically for a subsequent repeat LR, illustrated by a shortened hospital stay for the patient reported here. Thus, LLR is a powerful localized therapy which can be applied repeatedly and may prolong the survival of patients with multicentric metachronous HCCs/CLD.

\section{Financial support and sponsorship} None.

\section{Conflicts of interest}

There are no conflicts of interest.

\section{Patient consent}

Obtained.

\section{Ethics approval}

The patient was treated within the standards of our institute and the report was approved. 


\section{REFERENCES}

1. Reich H, McGlynn F, DeCaprio J, Budin R. Laparoscopic excision of benign liver lesions. Obstet Gynecol 1991;78:956-8.

2. Kaneko H, Tsuchiya M, Otsuka Y, Yajima S, Minagawa T, Watanabe M, Tamura A. Laparoscopic hepatectomy for hepatocellular carcinoma in cirrhotic patients. J Hepatobiliary Pancreat Surg 2009;16:433-8.

3. Morise Z, Ciria R, Cherqui D, Chen KH, Belli G, Wakabayashi G. Can we expand the indications for laparoscopic liver resection? A systematic review and meta-analysis of laparoscopic liver resection for patients with hepatocellular carcinoma and chronic liver disease. J Hepatobiliary Pancreat Sci 2015;22:342-52.

4. Takahara T, Wakabayashi G, Beppu T, Aihara A, Hasegawa K, Gotohda N, Hatano E, Tanahashi Y, Mizuguchi T, Kamiyama T, Ikeda T, Tanaka S, Taniai N, Baba H, Tanabe M, Kokudo N, Konishi M, Uemoto S, Sugioka A, Hirata K, Taketomi A, Maehara Y, Kubo S, Uchida E, Miyata H, Nakamura M, Kaneko H, Yamaue H, Miyazaki M, Takada T. Long-term and perioperative outcomes of laparoscopic versus open liver resection for hepatocellular carcinoma with propensity score matching: a multi-institutional Japanese study. $J$ Hepatobiliary Pancreat Sci 2015;22:721-7.

5. Buell JF, Cherqui D, Geller DA, O’Rourke N, Iannitti D, Dagher I, Koffron AJ, Thomas M, Gayet B, Han HS, Wakabayashi G, Belli G, Kaneko H, Ker CG, Scatton O, Laurent A, Abdalla EK, Chaudhury P, Dutson E, Gamblin C, D'Angelica M, Nagorney D, Testa G, Labow D, Manas D, Poon RT, Nelson H, Martin R, Clary B, Pinson WC, Martinie J, Vauthey JN, Goldstein R, Roayaie S, Barlet D, Espat J, Abecassis M, Rees M, Fong Y, McMasters KM, Broelsch C, Busuttil R, Belghiti J, Strasberg S, Chari RS; World Consensus Conference on Laparoscopic Surgery. The international position on laparoscopic liver surgery: The Louisville Statement, 2008. Ann Surg 2009;250:825-30.

6. Tsuchiya M, Otsuka Y, Tamura A, Nitta H, Sasaki A, Wakabayashi G, Kaneko H. Status of endoscopic liver surgery in Japan: a questionnaire survey conducted by the Japanese Endoscopic Liver Surgery Study Group. J Hepatobiliary Pancreat Surg 2009;16:405-9.

7. Wakabayashi G, Cherqui D, Geller DA, Buell JF, Kaneko H, Han HS, Asbun H, O’Rourke N, Tanabe M, Koffron AJ, Tsung A, Soubrane O, Machado MA, Gayet B, Troisi RI, Pessaux P, Van Dam RM, Scatton O, Abu Hilal M, Belli G, Kwon CH, Edwin B, Choi GH, Aldrighetti LA, Cai X, Cleary S, Chen KH, Schön MR, Sugioka A, Tang CN, Herman P, Pekolj J, Chen XP, Dagher I, Jarnagin W, Yamamoto M, Strong R, Jagannath P, Lo CM, Clavien PA, Kokudo N, Barkun J, Strasberg SM. Recommendations for laparoscopic liver resection: a report from the second international consensus conference held in Morioka. Ann Surg 2015;261:619-29.

8. Tomishige H, Morise Z, Kawabe N, Nagata H, Ohshima H, Kawase J, Arakawa S, Yoshida R, Isetani M. Caudal approach to pure lparoscopic posterior sectionectomy under the laparoscopy-specific view. World J Gastrointest Surg 2013;5:173-7.

9. Soubrane O, Schwarz L, Cauchy F, Perotto LO, Brustia R, Bernard D, Scatton O. A conceptual technique for laparoscopic right hepatectomy based on facts and oncologic principles: the caudal approach. Ann Surg 2015;261:1226-31.

10. Morise Z, Kawabe N, Tomishige H, Nagata H, Kawase J, Arakawa $\mathrm{S}$, Isetani M. How far can we go with laparoscopic liver resection for hepatocellular carcinoma? Laparoscopic sectionectomy of the liver combined with the resection of the major hepatic vein main trunk. Biomed Res Int 2015;2015:960752.

11. Yoon YS, Han HS, Cho JY, Kim JH, Kwon Y. Laparoscopic liver resection for centrally located tumors close to the hilum, major hepatic veins, or inferior vena cava. Surgery 2013;153:502-9.

12. Torzilli G, Donadon M, Marconi M, Botea F, Palmisano A, Del Fabbro D, Procopio F, Montorsi M. Systematic extended right posterior sectionectomy: a safe and effective alternative to right hepatectomy. Ann Surg 2008;247:603-11.

13. Belli G, Cioffi L, Fantini C, D’Agostino A, Russo G, Limongelli
P, Belli A. Laparoscopic redo surgery for recurrent hepatocellular carcinoma in cirrhotic patients: feasibility, safety, and results. Surg Endosc 2009;23:1807-11.

14. Nguyen KT, Laurent A, Dagher I, Geller DA, Steel J, Thomas MT, Marvin M, Ravindra KV, Mejia A, Lainas P, Franco D, Cherqui D, Buell JF, Gamblin TC. Minimally invasive liver resection for metastatic colorectal cancer: a multi-institutional, international report of safety, feasibility, and early outcomes. Ann Surg 2009;250:842-8.

15. Hu M, Zhao G, Xu D, Liu R. Laparoscopic repeat resection of recurrent hepatocellular carcinoma. World J Surg 2011;35:648-55.

16. Tsuchiya M, Otsuka Y, Maeda T, Ishii J, Tamura A, Kaneko H. Efficacy of laparoscopic surgery for recurrent hepatocellular carcinoma. Hepatogastroenterology 2012;59:1333-7.

17. Ahn KS, Han HS, Yoon YS, Cho JY, Kim JH. Laparoscopic liver resection in patients with a history of upper abdominal surgery. World J Surg 2011;35:1333-9.

18. Shafaee Z, Kazaryan AM, Marvin MR, Cannon R, Buell JF, Edwin B, Gayet B. Is laparoscopic repeat hepatectomy feasible? A triinstitutional analysis. J Am Coll Surg 2011;212:171-9.

19. Cannon RM, Brock GN, Marvin MR, Buell JF. Laparoscopic liver resection: an examination of our first 300 patients. J Am Coll Surg 2011;213:501-7.

20. Isetani M, Morise Z, Kawabe N, Tomishige H, Nagata H, Kawase $\mathrm{J}$, Arakawa S. Pure laparoscopic hepatectomy as repeat surgery and repeat hepatectomy. World J Gastroenterol 2015;21:961-8.

21. Shelat VG, Serin K, Samim M, Besselink MG, Al Saati H, Gioia PD, Pearce NW, Abu Hilal M. Outcomes of repeat laparoscopic liver resection compared to the primary resection. World J Surg 2014:38:3175-80

22. Kanazawa A, Tsukamoto T, Shimizu S, Kodai S, Yamamoto S, Yamazoe S, Ohira G, Nakajima T. Laparoscopic liver resection for treating recurrent hepatocellular carcinoma. J Hepatobiliary Pancreat Sci 2013;20:512-7.

23. Montalti R, Berardi G, Laurent S, Sebastiani S, Ferdinande L, Libbrecht LJ, Smeets P, Brescia A, Rogiers X, de Hemptinne B, Geboes K, Troisi RI. Laparoscopic liver resection compared to open approach in patients with colorectal liver metastases improves further resectability: oncological outcomes of a case-control matched-pairs analysis. Eur J Surg Oncol 2014;40:536-44.

24. Beck DE, Ferguson MA, Opelka FG, Fleshman JW, Gervaz P, Wexner SD. Effect of previous surgery on abdominal opening time. Dis Colon Rectum 2000;43:1749-53.

25. Wiebke EA, Pruitt AL, Howard TJ, Jacobson LE, Broadie TA, Goulet RJ Jr, Canal DF. Conversion of laparoscopic to open cholecystectomy. An analysis of risk factors. Surg Endosc 1996;10:742-5.

26. Wu JM, Lin HF, Chen KH, Tseng LM, Tsai MS, Huang SH. Impact of previous abdominal surgery on laparoscopic appendectomy for acute appendicitis. Surg Endosc 2007;21:570-3

27. Law WL, Lee YM, Chu KW. Previous abdominal operations do not affect the outcomes of laparoscopic colorectal surgery. Surg Endosc 2005;19:326-30.

28. Curet MJ. Special problems in laparoscopic surgery. Previous abdominal surgery, obesity, and pregnancy. Surg Clin North Am 2000;80:1093-110.

29. Nunobe S, Hiki N, Fukunaga T, Tokunaga M, Ohyama S, Seto Y, Yamaguchi T. Previous laparotomy is not a contraindication to laparoscopy-assisted gastrectomy for early gastric cancer. World $J$ Surg 2008;32:1466-72.

30. Szomstein S, Lo Menzo E, Simpfendorfer C, Zundel N, Rosenthal RJ Laparoscopic lysis of adhesions. World J Surg 2006;30:535-40.

31. Morise Z, Sugioka A, Kawabe N, Umemoto S, Nagata H, Ohshima H, Kawase J, Arakawa S, Yoshida R. Pure laparoscopic hepatectomy for hepatocellular carcinoma patients with severe liver cirrhosis. Asian J Endosc Surg 2011;4:143-6.

32. Morise Z. Pure Laparoscopic Hepatectomy for HCC Patients. In: Lau WY, editor. Hepatocellular Carcinoma - Clinical Research. Rijeka, Croatia: InTech; 2012. p. 183-96. 